\title{
May Bacterial Infections Trigger Bullous Pemphigoid? Case Report and Review of Literature
}

\author{
Michela Ileen Biondo ${ }^{1,+}$, Chiara Fiorentino ${ }^{1,+}{ }^{,}$, Severino Persechino ${ }^{2}$, Antonella Tammaro $^{2}{ }^{(D}$, Angela Koverech $^{1}$, \\ Armando Bartolazzi ${ }^{1}$, Salvatore Raffa ${ }^{1} \mathbb{D}$, Marco Canzoni ${ }^{1} \mathbb{D}$, Andrea Picchianti-Diamanti ${ }^{1}{ }^{1}$, Roberta Di Rosa ${ }^{1}$, \\ Giovanni Di Zenzo ${ }^{3}$, Enrico Scala ${ }^{3}$, Giorgia Meneguzzi ${ }^{1}$, Claudia Ferlito ${ }^{1}$, Milica Markovic ${ }^{1}$, Sara Caporuscio ${ }^{1}$, \\ Maria Laura Sorgi ${ }^{1}$, Simonetta Salemi ${ }^{1, *}$ and Bruno Laganà ${ }^{1, *(\mathbb{D})}$
}

check for updates

Citation: Biondo, M.I.; Fiorentino, C.; Persechino, S.; Tammaro, A.;

Koverech, A.; Bartolazzi, A.; Raffa, S.;

Canzoni, M.; Picchianti-Diamanti, A.;

Di Rosa, R.; et al. May Bacterial

Infections Trigger Bullous

Pemphigoid? Case Report and

Review of Literature. Microorganisms

2021, 9, 1235. https://doi.org/

$10.3390 /$ microorganisms 9061235

Academic Editor: Ruth Serra-Moreno

Received: 20 March 2021

Accepted: 4 June 2021

Published: 7 June 2021

Publisher's Note: MDPI stays neutral with regard to jurisdictional claims in published maps and institutional affiliations.

Copyright: (c) 2021 by the authors. Licensee MDPI, Basel, Switzerland. This article is an open access article distributed under the terms and conditions of the Creative Commons Attribution (CC BY) license (https:/ / creativecommons.org/licenses/by/ $4.0 /)$.
1 Dipartimento di Medicina Clinica e Molecolare, Sapienza, Università di Roma, AOU S. Andrea, 00189 Roma, Italy; biondo_michela@yahoo.it (M.I.B.); chiara.fiorentino@hotmail.it (C.F.); angelakoverech@gmail.com (A.K.); armando.bartolazzi@ospedalesantandrea.it (A.B.); salvatore.raffa@uniroma1.it (S.R.); canzonimarco@gmail.com (M.C.); andrea.picchiantidiamanti@uniroma1.it (A.P.-D.); roberta.dirosa@uniroma1.it (R.D.R.); giorgia.meneguzzi@hotmail.it (G.M.); clau.ferlito@gmail.com (C.F.); minamarkovic@hotmail.com (M.M.); sara.caporuscio1@gmail.com (S.C.); marialaura.sorgi@uniroma1.it (M.L.S.)

2 UOD di Dermatologia, Sapienza, Università di Roma, AOU S. Andrea, 00189 Roma, Italy; severino.persechino@uniroma1.it (S.P.); antonella.tammaro@uniroma1.it (A.T.)

3 Istituto Dermopatico dell'Immacolata, 00167 Roma, Italy; g.dizenzo@idi.it (G.D.Z.); e.scala@idi.it (E.S.)

* Correspondence: simonetta.salemi@uniroma1.it (S.S.); bruno.lagana@uniroma1.it (B.L.)

+ These authors contributed equally to the study.

Abstract: Bullous pemphigoid (BP) is an autoimmune blistering skin disease, mainly observed in the elderly. Infections have been suggested as possible disease triggers. However, infections may even heavily influence the disease clinical course and mortality. A 75-year-old woman was admitted to hospital for severe erythematosus blistering disease, accompanied by hyper-eosinophilia and hyperIgE. The culture of bullous fluid was positive for Enterococcus faecalis, the blood culture was positive for Staphylococcus aureus, and the urine culture was positive for Proteus mirabilis and Escherichia coli. Moreover, circulating anti-BP180 IgG was present and the histopathological/ultrastructural examination of a lesional skin biopsy was compatible with BP. High eosinophil levels (up to $3170 / \mu \mathrm{L}$ ) were found throughout the clinical course, while values below $1000 / \mu \mathrm{L}$ were associated with clinical improvement. The total IgE was $1273 \mathrm{IU} / \mathrm{mL}$, and specific anti-G/V-penicillin/ampicillin $\operatorname{IgE}$ antibodies were positive. The patient had a complete clinical recovery in two months with methyl-prednisolone (40 then $20 \mathrm{mg} /$ day) and low-dose azathioprine (50 mg/day) as a steroidsparing agent. The steroid treatment was tapered until interruption during a one-year period and intravenous immunoglobulins have been administered for three years in order for azathioprine to also be interrupted. The patient stopped any treatment five years ago and, in this period, has always been in good health. In this case, the contemporaneous onset of different bacterial infections and BP is suggestive of bacterial infections acting as BP trigger(s), with allergic and autoimmune pathways contributing to the disease pathogenesis.

Keywords: bullous pemphigoid (BP); infections; autoimmunity; IVIg

\section{Introduction}

Bullous pemphigoid (BP) is the most frequent of the rare autoimmune bullous skin diseases [1]. It is characterized by subepidermal blistering caused by autoantibodies directed against the hemidesmosomal proteins BP180 and BP230 [2,3]. Its incidence in Europe ranges from 4.47 to $13.4 / 1,000,000$ person-years [4,5], occurring preferentially in the elderly, without a net predilection for sex [6]. BP is more frequently observed after the seventh decade, but particularly after the ninth decade of age [7]. The mortality is lower in the USA, but in Europe, it may be as high as $19-40 \%$ in the first year after flare [8]. A 
significant association with the major histocompatibility complex class II allele HLA-DQB1* 0301 was already observed in 1996 [9].

Several conditions have been considered risk factors for BP development: patients with BP are more likely to have various neurological diseases, including stroke, epilepsy, multiple sclerosis, Parkinson's disease, dementia, and bedridden condition [10]. The association of BP with malignancy is controversial [11,12]. Despite the inability of a trigger to be identified in the large majority of BP cases [1], known agents/events involved in triggering $\mathrm{BP}$ include drugs, trauma, burns, ultraviolet radiation, radiotherapy, and vaccinations, particularly against influenza [8]. Recently, infectious agents have also been suggested as possible BP-inducers $[6,10]$. However, the relationship between infections and BP is not only limited to the infections as possible disease-trigger agents, but they may represent a frequent and severe complication [13], even in consideration of the immunosuppressive effect of therapy, capable of heavily influencing the clinical course and the mortality rate [14].

The disease pathogenesis is linked to the effect of anti-BP180 and anti-BP230 autoantibodies, which may link their respective antigens at the dermal-epidermal basement membrane (BM) and complement activation, so that chemotactic factors are released to attract inflammatory cells able to release proteases, free oxygen radicals, and leukotrienes, such as neutrophils, mast-cells, eosinophils, and macrophages. The consequent inflammation is responsible for local damage, with detachment of the epidermis from the dermis at the BM level $[2,14]$. The anti-BP180 and BP230 autoantibodies are of IgG isotype (including IgG1 and IgG4 subclasses), but also of IgA and IgE. IgE autoantibodies may be observed in up to $86 \%$ of untreated BP patients [15]. This, together with the relevant pathogenetic role of eosinophils $[16,17]$, underlines the tight interrelationship between allergic and autoimmune immunopathogenic mechanisms, which tightly synergize to induce the tissue damage. Recently, the immunopathologic role of the cytokine IL17A has also been identified [18], thus providing the suggestion for a further therapeutic approach, represented by anti-IL17A monoclonal antibodies. However, autoimmunity is not only witnessed by the identification of antibodies of different isotypes recognizing autoantigens, but also by the demonstration of the epitope spreading phenomenon; in fact, the autoantibodies are initially exclusively directed toward the extracellular component NC16A of the BP180 transmembrane autoantigen, whereas, subsequently, autoantibodies directed toward the intracellular component appear [2].

The diagnosis is based on clinical characteristics, which, in the bullous phase, are easy to be recognized, and on laboratory features, such as histology with the demonstration of a linear deposit of IgG and/or C3 at the dermal-epidermal BM by direct immunofluorescence microscopy of a perilesional skin biopsy and the detection of serum autoantibodies against BP180 and/or BP230 [14].

A BP patient in whom multiple bacterial infections have been simultaneously documented with the BP flare is described here.

\section{Case Report}

A 75-year-old woman was admitted to the Clinical Immunology unit of the S. Andrea University Hospital because of an itchy rash characterized by bullous hemorrhagic lesions over an erythematous base, which appeared 6 days before and gradually spread to the entire body, with no mucosal involvement (Figure 1). The condition was also accompanied by fever $\left(38^{\circ} \mathrm{C}\right)$, cognitive impairment, and lack of self-sufficiency. 


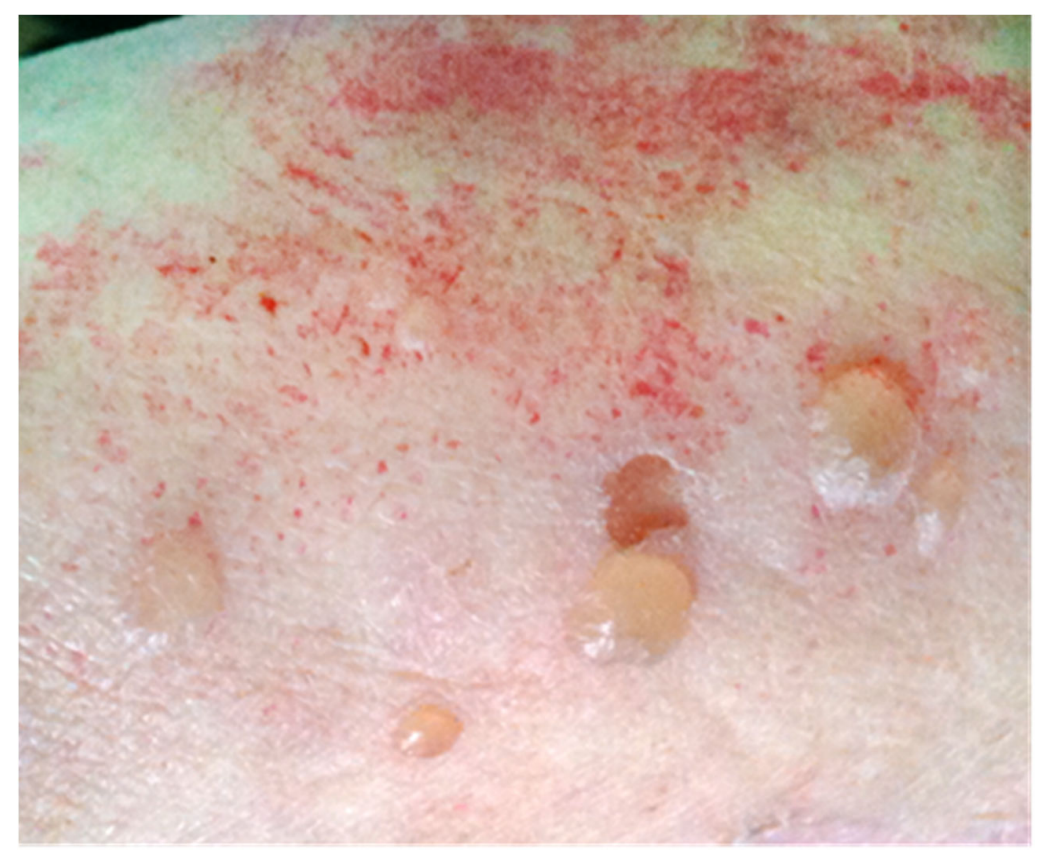

Figure 1. Blistering skin lesions on erythematous base on the right arm.

She had a history of type 2 diabetes, hypertension, and stroke ( 5 years before), resulting in hemiplegia of the upper and lower right limbs; no history of allergy, autoimmunity, or cancer was referred. The patient had been on furosemide and vildagliptin for one year.

Laboratory tests revealed severe hyponatremia $(120 \mathrm{mmol} / \mathrm{L})$, leukocytosis $(18,640 / \mu \mathrm{L})$, moderate anemia $(\mathrm{Hb} 10 \mathrm{~g} / \mathrm{dL})$, and increased C-reactive protein $(2.9 \mathrm{mg} / \mathrm{dL})$, whereas the serum protein electrophoresis showed high $\alpha 2$-globulin $(0.9 \mathrm{~g} / \mathrm{dL})$ and low $\gamma$-globulin $(0.5 \mathrm{~g} / \mathrm{dL})$ levels. Serum immunoglobulin (Ig) values were: IgG $684 \mathrm{mg} / \mathrm{dL}, \mathrm{IgA} 158 \mathrm{mg} / \mathrm{dL}$, IgM $29 \mathrm{mg} / \mathrm{dL}$, and IgE 1,273 IU/mL. Blood cell counts revealed hyper-eosinophilia $(3170 / \mu \mathrm{L}$; normal values $<500 / \mu \mathrm{L})$; during the over 1-month permanence in the hospital, eosinophils presented a fluctuating trend (median 1132; range $40-3170 / \mu \mathrm{L}$ ), with peaks alternating with lower (even normal) values, which were associated with clinical improvement. Serum anti-BP180 IgG was tested by the commercial enzyme-like immunosorbent assay (ELISA, MBL, Nagoja, Japan) and resulted positive (129.7 U/mL, normal values $\leq 9)$, whereas anti-BP230 resulted negative. Lesions were monitored with the BP Disease Area Index (BPDAI) [19]. The score at diagnosis was 70/120.

Intravenous methyl-prednisolone ( 40 then $20 \mathrm{mg}$ /day) was administered, and hyponatremia was gradually corrected, whereas furosemide and vildagliptin were discontinued on suspicion of drug responsibility in the BP induction.

Histopathological and ultrastructural examination of a perilesional and lesional skin biopsy showed a pattern compatible with BP (Figure 2). 

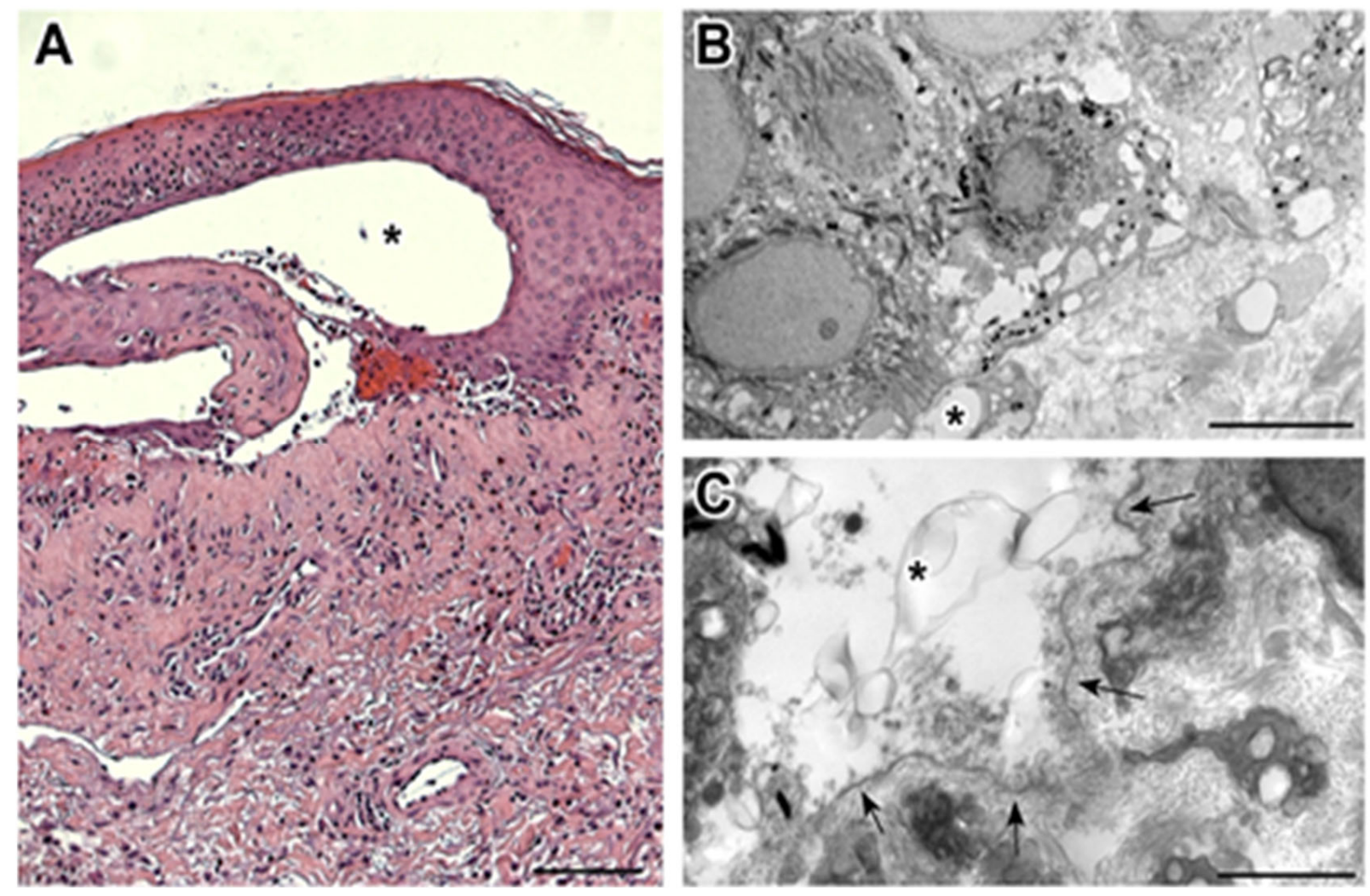

Figure 2. (A) The bullous lesion at histopathologic examination is composed of a subepidermal blister $\left(^{*}\right)$, with underlying sclerosis of the papillary component of the dermis, dilated capillary vessels, and perivascular chronic lymphocytic infiltrate with an eosinophilic component. A significant actinic elastosis is visible in the reticular dermis. (Hematoxylin/eosin staining; 100× magnification; bar $100 \mu \mathrm{m}$ ). (B) Transmission electron microscopy performed on the perilesional skin reveals the presence of small subepidermal blisters $\left(^{*}\right)$ without epidermal basal cell damage (uranyl acetate/lead citrate; bar: $5 \mu \mathrm{m}$ ). (C) Ultrastructural analysis of lesional skin shows the formation of a blister ${ }^{*}$ ) between the basal keratinocytes and the partially fragmented lamina densa (arrows), which defines the floor of the blister (uranyl acetate/lead citrate; bar: $2 \mu \mathrm{m})$.

Cultures of the bullous fluid revealed the growth of Enterococcus faecalis, and one blood culture was positive for Staphylococcus aureus. The urine culture was positive for Proteus mirabilis and Escherichia coli. The patient underwent antibiotic therapy with intravenous ampicillin $(1 \mathrm{~g} \times 2$ /day for 6 days) followed by piperacillin plus tazobactam $(4.5 \mathrm{~g} \times 2$ /day for 6 days) and, subsequently, linezolid (500 $\mathrm{mg} \times 2$ /day for 7 days) and meropenem $(1 \mathrm{~g} \times 2$ /day for 5 days), according to antibiogram results. Radio-allergo-sorbent tests (RASTs) for G and V penicillins, as well as for ampicillin, were positive. Skin lesions were locally treated with boric acid solution $3 \%$ and eosin solution $2 \%$.

At discharge, the patient was apyretic, had recovered her level of self-sufficiency, and appeared fully oriented. Azathioprine (50 mg/day) was started and intravenous steroid was moved to oral administration (prednisone $25 \mathrm{mg} /$ day). Itching still persisted, whereas, at clinical examination, total skin recovery was observed. Blood tests showed normal levels of leukocytes and reduced hyper-eosinophilia (leukocytes $8960 / \mu \mathrm{L}$ and eosinophils $1057 / \mu \mathrm{L}$ ), whereas hypogammaglobulinemia persisted ( $\mathrm{x}$-globulins $0.56 \mathrm{~g} / \mathrm{dL}$; IgG $490 \mathrm{mg} / \mathrm{dL}$ ) and C-reactive protein was still increased $(4.3 \mathrm{mg} / \mathrm{dL})$. The gradual tapering of the steroid dose up to its interruption was completed in one year, the azathioprine was stopped after two years, whereas the periodical infusion of intravenous immunoglobulins (IVIg, $1 \mathrm{~g} / \mathrm{kg}$ monthly) was continued for one further year [20]. The patient stopped any treatment five years ago and, in this period, has always been in good health. A brief summary of the clinical and laboratory characteristics of the patient at admission to the hospital and at discharge is reported in Table 1. 
Table 1. Clinical and laboratory patient characteristics at admission to and discharge from the hospital.

\begin{tabular}{ll}
\hline \multicolumn{1}{c}{ Admission } & \multicolumn{1}{c}{ Discharge } \\
\hline Clinical conditions & Clinical Conditions \\
- Fever $38^{\circ} \mathrm{C}$ & $\bullet$ Apyretic \\
- Diffuse bullous hemorrhagic rash/no mucosal & $\bullet$ Skin recovered/itching persisted \\
involvement & $\bullet$ Oriented/self-sufficient
\end{tabular}

\section{Cultures}

- $\quad$ Blood: S. aureus

- $\quad$ Blister fluid: E. faecalis

- $\quad$ Urine: P. mirabilis and E. coli

\section{Cultures}

- Negative

- Negative

- Negative

$\begin{array}{ll}\text { Allergy } & \text { Allergy } \\ \text { - Hyper-eosinophilia }(3170 / \mu \mathrm{L}) & \bullet \quad \text { Hyper-eosinophilia }(1057 / \mu \mathrm{L}) \\ \text { - Hyper-IgE }(1273 \mathrm{IU} / \mathrm{mL}) & \bullet \mathrm{ND} \\ \text { - } \quad \text { RAST+ for } \mathrm{G} / \mathrm{V} \text { penicillins and ampicillin } & \bullet \mathrm{ND}\end{array}$

\section{Autoimmunity}

- $\quad$ Antibodies anti-BP180 (129.7 U/mL)

\section{Autoimmunity}

- ND

\section{Laboratory tests}

- $\quad$ Leukocytosis $(18,640 / \mu \mathrm{L})$

- Moderate anemia ( $\mathrm{Hb} 10 \mathrm{~g} / \mathrm{dL})$

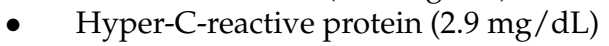

- Hyper- $\alpha 2$-globulinemia $(0.9 \mathrm{~g} / \mathrm{dL})$

- Hypo-y-globulinemia $(0.5 \mathrm{~g} / \mathrm{dL})$

- Hypo-IgG (684 mg/dL)

- Hyponatremia $(120 \mathrm{mmol} / \mathrm{L})$

\section{Laboratory tests}

- $\quad$ Leukocytes $(8960 / \mu \mathrm{L})$

- $\quad$ Moderate anemia $(\mathrm{Hb} 8.7 \mathrm{~g} / \mathrm{dL})$

- Hyper-C-reactive protein $(4.3 \mathrm{mg} / \mathrm{dL})$

- $\quad$ Normal $\alpha 2$-globulinemia $(0.66 \mathrm{~g} / \mathrm{dL})$

- Hypo- - -globulinemia $(0.56 \mathrm{~g} / \mathrm{dL})$

- Hypo-IgG (550 mg/dL)

- Normal natremia (138 $\mathrm{mmol} / \mathrm{L})$

\section{Biopsy perilesional skin}

- Histopathology: subepidermal blister, perivascular lymphocytic infiltrate with eosinophils

- Ultrastructural analysis: small subepidermal blisters without epidermal basal cell damage
Biopsy perilesional skin

- ND

- $\quad \mathrm{ND}$

\section{Treatment}

- $\quad$ Furosemide interrupted

- Vildagliptin interrupted

- Ampicillin $(1 \mathrm{~g} \times 2$ /day iv for 6 days $)$

- $\quad$ Piperacillin/Tazobactam (4.5 $\mathrm{g} \times 2$ /day iv for 5 days)

- $\quad$ Linezolid (500 mg $\times 2 /$ day iv for 7 days)

- Meropenem $(1 \mathrm{~g} \times 2 /$ day iv for 5 days $)$

- Hyponatremia gradual correction

- Methyl-prednisolone (40 then $20 \mathrm{mg}$ /day iv)
Treatment

- $\quad$ Prednisone (25 mg/day for $1 \mathrm{yr})$

- $\quad$ Azathioprine (50 mg/day for $2 \mathrm{yr}$ )

- $\quad \operatorname{IVIg}(1 \mathrm{~g} / \mathrm{kg} / \mathrm{month}$, for $3 \mathrm{yr})$

\section{RAST = radio-allergo-sorbent-test; $\mathrm{ND}=$ not done; iv = intravenously .}

\section{Discussion}

In the case described here, BP has been diagnosed on the basis of the criteria needed for a BP diagnosis to be made, which is a compatible clinical picture, histology, even supported by ultrastructural analysis, and the presence of circulating anti-BP180 autoantibodies identified by ELISA. In fact, the anti-BP180 and BP230 hemidesmosomal proteins IgE, IgG1, and IgG4 antibody production [21] have been reported as a BP hallmark. BP180 and BP230 play structural roles in stratified epithelia, and their immune-mediated damage causes a 
dermo-epidermal cleavage, with resulting blister formation. This pathological sequence involves mast cell degranulation [22,23].

The BP180/BP230 expression in the central nervous system [24] may provide the basis for the BP association with neurological diseases [25]. In the patient described here, the previous stroke, with consequent hemiplegia and bedridden condition, is in line with the well-known BP risk factors. The tight correlation between clinical worsening or improvement and eosinophil counts allows one to hypothesize a pathogenetic role for eosinophils in this specific case, thus suggesting a drug-induced pathogenesis, even though a BP-associated hyper-eosinophilia independent of an allergic state has been described [26].

The association between BP occurrence and both furosemide [27,28] and vildagliptin [29] administration has been reported in the literature. Several BP cases associated with furosemide intake have been described $[27,28]$, and different possible pathogenetic mechanisms have been hypothesized, although formal demonstrations have seldom been achieved [8]. Loop diuretics have been used more frequently in BP-developing patients in a case-control study [30]. Takeishi et al. described a BP case correlated with furosemide intake and sunlight exposure, suggesting that furosemide may act as a photosensitizer [31]. Panayiotou reported two more elderly patients with heart failure, in whom BP appeared with intravenous furosemide intake and resolved after its discontinuation [32]. Vildagliptin belongs to the group of oral dipeptyl peptidase-4 inhibitors (DPP-4is). Several cases of DPP-4is (especially vildagliptin)-induced BP have recently been reported and epidemiological studies have corroborated such an association, even though the pathogenetic process still remains largely unknown [33].

The timing of new lesion onset and the specific $\mathrm{IgE}$ test results support a reaction also against beta-lactamic ring antibiotics; in fact, after antibiotic therapy discontinuation, a progressive improvement was observed, without new bullous lesions. However, the clinical improvement may even be interpreted as a consequence of the healing from infections. In fact, the above-reported hypothesized drug-induced pathogenesis does not exclude other possible triggers possibly being involved. Infections have traditionally been considered possible triggers of autoimmunity [34] and, more recently, they have even been suggested as possible BP inducers [8] (Table 2). Human herpesviruses have been found in blister fluid of BP patients [35] and serological association has even been observed [6]. The Torque Teno virus has been selectively found to be associated with BP [36], as well as human immunodeficiency virus (HIV) [37-39], hepatitis C virus (HCV) [40], and hepatitis B virus (HBV) [6]. Even coxsackievirus A6 has been reported to be able to induce a BP flare [41]. Moreover, bacterial infections, such as Helicobacter pylori [6] and the bacteria involved in erysipelas [42], have also been found to be BP-associated. Finally, even parasites, such as Toxoplasma gondii [6] and Sarcoptes scabiei [43], have been associated with BP. In the patient described here, the culture of blister fluid was positive for E. faecalis, the blood culture was positive for S. aureus, and the urine culture was positive for P. mirabilis and E. coli. All these simultaneous infections were probably determined by the lack of selfsufficiency and humoral immunodepression, documented by the low serum levels of $\gamma$-globulins and IgG. In fact, it is well-known that older age is accompanied by immunesenescence [44], with a significant functional reduction of different immune compartments, including the humoral one, with a defective response to vaccines, a reduced number of memory B cells, and reduced levels of circulating immunoglobulins. Infections and chronic inflammatory diseases can act on this predisposing substrate and induce a worsening of the immune system function [45]. The positivity of blood culture for S. aureus, a microorganism frequently found associated with erysipelas, which, in turn, has been described as BPassociated, and the positivity of blister fluid for E. faecalis, are both suggestive elements for a possible bacterial responsibility in triggering BP. However, the induction of autoimmune reactions by bacteria was known for long time, through the molecular mimicry mechanism, as in rheumatic fever and Streptococcus $\beta$ hemolytic group $A$, or through the bystander activation [46]. Even the improvement observed after the end of antibiotic therapy and the successful treatment with IVIg, a cross-road between an anti-infective and an immune- 
modulating treatment, is a further clue to suspect that the sudden burst of the blistering autoimmune disease may have been induced by an infectious trigger, the removal of which was parallel to the clinical BP improvement. Although IVIg has been empirically used at a dose that is half that generally indicated in autoimmune diseases and has recently been demonstrated effective in BP through a randomized study [47], they were highly effective and induced a disease stabilization.

Table 2. Infectious agents suspected of acting as triggers of bullous pemphigoid and type of diagnosis of infection.

\begin{tabular}{|c|c|c|c|c|c|}
\hline Microorganisms/Infections & Clinical & Cultural & Microscopic/Molecular & Serological & References \\
\hline CMV-EBV-HHV6-HHV8 & & & $\mathrm{x}$ & $\mathrm{x}$ & {$[6,35]$} \\
\hline Torque Teno virus & & & $x$ & & [36] \\
\hline HIV & & & $\mathrm{x}$ & & [37-39] \\
\hline HBV & & & & $x$ & [6] \\
\hline $\mathrm{HCV}$ & & & $x$ & & [40] \\
\hline Coxsakievirus A6 & $x$ & & & & [41] \\
\hline Helicobacter pylori & & & & $x$ & [6] \\
\hline Erysipelas & $x$ & & & & {$[42]$} \\
\hline Toxoplasma gondii & & & & $x$ & [6] \\
\hline Sarcoptes scabiei & $x$ & & $x$ & & [43] \\
\hline Staphylococcus aureus & & Blood & & & This case \\
\hline Enterococcus faecalis & & Blister fluid & & & This case \\
\hline
\end{tabular}

CMV = Cytomegalovirus; EBV = Epstein-Barr virus; HHV6/HHV8 = Human Herpesvirus 6/8; HIV = Human Immunodeficiency virus; $\mathrm{HBV}=$ Hepatitis $B$ virus; $\mathrm{HCV}=$ Hepatitis $C$ virus .

Autoimmune and allergic diseases share important features; one of the potential common elements may be represented by mast cells, which have recently been found to be involved in the development of autoimmune diseases, such as rheumatoid arthritis, type I diabetes, multiple sclerosis, and BP [48]. In BP, mast cells play a key role in neutrophil recruitment [22]. Allergic and autoimmune mechanisms seem to be strictly interwoven in the pathogenesis of the current case and supported by detection of hyper-IgE, hypereosinophilia, the presence of anti-G/V penicillins and ampicillin IgE, the detection of autoantibodies to BP180, and indirect signs of BP180-anti-BP180IgG immune complexes at the dermal-epidermal junction as well.

\section{Conclusions}

The patient described here is the first, to the best of our knowledge, in whom bacterial pathogens have been isolated and identified contemporaneously with a BP flare, thus suggesting that bacterial infections may act as BP triggers. In fact, for H. pylori, only serology was analyzed, and, for erysipelas, the etiologic agent(s) has(ve) not been identified. The easy BP diagnosis allows one to establish with certainty that the onset of autoimmune disease and bacterial infections is contemporaneous, thus making this case report a clear example of the tight, possibly pathogenetic, relationship between infections and autoimmune diseases. Conversely, the simultaneous positivity of four different bacterial pathogens is a further confirmation that infections are a frequent and severe complication of BP, able to influence prognosis and to increase the mortality [49], in analogy to what may be observed in other autoimmune diseases [50]. In this context, the role of IVIg as an immunomodulating stabilizing agent in a BP case associated with many severe bacterial infections has to be underlined. Moreover, this case is a faithful expression of the synergy between autoimmune and allergic immunopathologic mechanisms in BP, a synergy that may even be observed only in few other autoimmune diseases, such as some cases of vasculitis, of which the anti-neutrophil cytoplasmatic antibody-associated eosinophilic granulomatosis with polyangiitis (formerly Churg-Strauss Syndrome), in which allergic and autoimmune clinical and laboratory manifestations are strictly interwoven, is the most representative example. 


\section{Ethic Statement}

The patient provided permission to publish clinical data anonymously.

Author Contributions: M.I.B., C.F. (Chiara Fiorentino), A.K., M.C., A.P.-D., R.D.R., G.D.Z., E.S., G.M., C.F. (Claudia Ferlito), M.M., S.C., M.L.S., S.S. and B.L. have designed and organized the study, analyzed and interpreted the results, and drafted the manuscript; S.P. and A.T. have managed the clinical case, A.B. has carried out histology, whereas S.R. has carried out the ultrastructural study. All the authors have substantively revised the work; AND have approved the submitted version (and the version substantially edited by the journal staff that involves the author's contribution to the study); AND have agreed to be personally accountable for the author's own contributions and for ensuring that questions related to the accuracy or integrity of any part of the work, even ones in which the author was not personally involved, are appropriately investigated, resolved, and documented in the literature. All authors have read and agreed to the published version of the manuscript.

Funding: This research received no external funding.

Institutional Review Board Statement: Not applicable.

Informed Consent Statement: Not applicable.

Data Availability Statement: Sant'Andrea University Hospital, Rome, Italy.

Acknowledgments: The authors wish to thank Giovanna Zambruno for having carried out the analysis of the serum autoantibodies anti-BP180 by enzyme-linked immunosorbent assay.

Conflicts of Interest: The authors declare no conflict of interest.

\section{References}

1. Bağc1, I.S.; Horváth, O.N.; Ruzicka, T.; Sárdy, M. Bullous pemphigoid. Autoimmun. Rev. 2017, 16, 45-455. [CrossRef]

2. Di Zenzo, G.; Marazza, G.; Borradori, L. Bullous pemphigoid: Physiopathology, clinical features and management. Adv. Dermatol. 2007, 23, 257-288. [CrossRef] [PubMed]

3. Schmidt, E.; Zillikens, D. Pemphigoid diseases. Lancet 2013, 381, 320-332. [CrossRef]

4. Parker, S.R.; MacKelfresh, J. Autoimmune blistering diseases in the elderly. Clin. Dermatol. 2011, 29, 69-79. [CrossRef]

5. Yancey, K.B. The pathophysiology of autoimmune blistering disorders. J. Clin. Investig. 2005, 115, 825-828. [CrossRef] [PubMed]

6. Sagi, L.; Baum, S.; Agmon-Levin, N.; Sherer, Y.; Katz, B.S.; Barzilai, O.; Ram, M.; Bizzaro, N.; SanMarco, M.; Trau, H.; et al. Autoimmune bullous diseases the spectrum of infectious agent antibodies and review of the literature. Autoimmun. Rev. 2011, 10, 527-535. [CrossRef]

7. Marazza, G.; Pham, H.C.; Schärer, L.; Pedrazzetti, P.P.; Hunziker, T.; Trüeb, R.M.; Hohl, D.; Itin, P.; Lautenschlager, S.; Naldi, L.; et al. Autoimmune bullous disease Swiss study group. Incidence of bullous pemphigoid and pemphigus in Switzerland: A 2-year prospective study. Br. J. Dermatol. 2009, 161, 861-868. [CrossRef]

8. Joly, P.; Benichou, J.; Lok, C.; Hellot, M.F.; Saiag, P.; Tancrede-Bohin, E.; Sassolas, B.; Labeille, B.; Doutre, M.S.; Gorin, I.; et al. Prediction of survival for patients with bullous pemphigoid: A prospective study. Arch. Dermatol. 2005, 141, 691-698. [CrossRef]

9. Delgado, J.C.; Turbay, D.; Yunis, E.J.; Yunis, J.J.; Morton, E.D.; Bhol, K.; Norman, R.; Alper, C.A.; Good, R.A.; Ahmed, R. A common major histocompatibility complex class II allele HLA-DQB1* 0301 is present in clinical variants of pemphigoid. Proc. Natl. Acad. Sci. USA 1996, 93, 8569-8571. [CrossRef]

10. Moro, F.; Fania, L.; Sinagra, J.L.M.; Salemme, A.; Zenzo, G.D. Bullous pemphigoid: Trigger and predisposing factors. Biomolecules 2020, 10, 1432. [CrossRef]

11. Balestri, R.; Magnano, M.; La Placa, M.; Patrizi, A.; Angileri, L.; Tengattini, V.; Bardazzi, F. Malignancies in bullous pemphigoid: A controversial association. J. Dermatol. 2015, 43, 125-133. [CrossRef]

12. Atzmony, L.; Mimouni, I.; Reiter, O.; Leshem, Y.A.; Taha, O.; Gdalevich, M.; Hodak, E.; Mimouni, D. Association of bullous pemphigoid with malignancy: A systematic review and meta-analysis. J. Am. Acad. Dermatol. 2017, 77, 691-699. [CrossRef] [PubMed]

13. Chen, J.; Mao, X.; Zhao, W.; Zhang, B.; Chen, X.; Yu, C.; Zheng, Z.; Jin, H.; Li, L. Assessment of the characteristics and associated factors of infectious complications in bullous pemphigoid. Front. Immunol. 2020, 11, 1607. [CrossRef] [PubMed]

14. Sadik, C.D.; Schmidt, E. Resolution in bullous pemphigoid. Semin. Immunopathol. 2019, 41, 645-654. [CrossRef]

15. Dimson, O.G.; Giudice, G.J.; Fu, C.L.; Van den Bergh, F.; Warren, S.J.; Janson, M.M.; Fairley, J.A. Identification of a potential effector function for IgE autoantibodies in the organ-specific autoimmune disease bullous pemphigoid. J. Investig. Dermatol. 2003, 120, 784-788. [CrossRef]

16. Simon, D.; Borradori, L.; Simon, H.U. Eosinophils as putative therapeutic targets in bullous pemphigoid. Exp. Dermatol. 2017, 26, 1187-1192. [CrossRef] [PubMed]

17. Diny, N.L.; Rose, N.R.; Čiháková, D. Eosinophils in autoimmune diseases. Front. Immunol. 2017, 8, 484. [CrossRef] 
18. Chakievska, L.; Holtsche, M.M.; Künstner, A.; Goletz, S.; Petersen, B.S.; Thaci, D.; Ibrahim, S.M.; Ludwig, R.J.; Franke, A.; Sadik, C.D.; et al. IL-17A is functionally relevant and a potential therapeutic target in bullous pemphigoid. J. Autoimmun. 2019, 96, 104-112. [CrossRef]

19. Murrell, D.F.; Daniel, B.S.; Joly, P.; Borradori, L.; Amagai, M.; Hashimoto, T.; Caux, F.; Marinovic, B.; Sinha, A.A.; Hertl, M.; et al. Definitions and outcome measures for bullous pemphigoid: Recommendations by an international panel of experts. J. Am. Acad. Dermatol. 2012, 66, 479-485. [CrossRef]

20. Hoffmann, J.H.O.; Enk, A.H. High-dose intravenous immunoglobulin in skin autoimmune disease. Front. Immunol. 2019, 10, 1090. [CrossRef] [PubMed]

21. Döpp, R.; Schmidt, E.; Chimanovitch, I.; Leverkus, M.; Bröcker, E.B.; Zillikens, D. IgG4 and IgE are the major immunoglobulins targeting the NC16A domain of BP180 in bullous pemphigoid: Serum levels of these immunoglobulins reflect disease activity. J. Am. Acad. Dermatol. 2000, 42, 577-583. [CrossRef] [PubMed]

22. Chen, R.; Ning, G.; Zhao, M.L.; Fleming, M.G.; Diaz, L.A.; Werb, Z.; Liu, Z. Mast cells play a key role in neutrophil recruitment in experimental bullous pemphigoid. J. Clin. Investig. 2001, 108, 1151-1158. [CrossRef] [PubMed]

23. Wintroub, B.U.; Mihm, M.C., Jr.; Goetzl, E.J.; Soter, N.A.; Austen, K.F. Morphologic and functional evidence for release of mast-cell products in bullous pemphigoid. N. Engl. J. Med. 1978, 298, 417-421. [CrossRef]

24. Seppänen, A.O. Both bullous pemphigoid antigens are expressed in the central nervous system. Br. J. Dermatol. 2012, 166, 683-684. [CrossRef]

25. Chen, Y.J.; Wu, C.Y.; Lin, M.W.; Chen, T.J.; Liao, K.K.; Chen, Y.C.; Hwang, C.Y.; Chu, S.Y.; Chen, C.C.; Lee, D.D.; et al. Comorbidity profiles among patients with bullous pemphigoid: A nationwide population-based study. Br. J. Dermatol. 2011, 165, 593-599. [CrossRef]

26. Belgnaoui, F.; Idrissi, M.; Benyoussef, K.; Loudiye, T.; Bella, A.; Senouci, K.; Aouni, M.; Mansouri, F.; Heid, E.; Hassam, B. Idiopathic hypereosinophilic syndrome and bullous pemphigoid. Ann. Dermatol. Venereol. 2002, 129, 1291-1294. [PubMed]

27. Lee, J.J.; Downham, T.F., II. Furosemide-induced bullous pemphigoid: Case report and review of literature. J. Drugs Dermatol. 2006, 5, 562-564.

28. Koch, C.A.; Mazzaferri, E.L.; Larry, J.A.; Fanning, T.S. Bullous pemphigoid after treatment with furosemide. Cutis 1996, 58, 340-344. [PubMed]

29. Skandalis, K.; Spirova, M.; Gaitanis, G.; Tsartsarakis, A.; Bassukas, I.D. Drug-induced bullous pemphigoid in diabetes mellitus patients receiving dipeptidyl peptidase-IV inhibitors plus metformin. J. Eur. Acad. Dermatol. Venereol. 2012, 26, 249-253. [CrossRef]

30. Walmsley, N.; Hampton, P. Bullous pemphigoid triggered by swine flu vaccination: Case report and review of vaccine triggered pemphigoid. J. Dermatol. Case Rep. 2011, 5, 74-76. [CrossRef]

31. Takeichi, S.; Kubo, Y.; Arase, S.; Hashimoto, T.; Ansai, D. Brunsting-Perry type localized bullous pemphigoid, possibly induced by furosemide administration and sun exposure. Eur. J. Dermatol. 2009, 19, 500-503. [CrossRef] [PubMed]

32. Panayiotou, B.N.; Prasad, M.V.; Zaman, M.N. Furosemide-induced bullous pemphigoid. Br. J. Clin. Pract. 1997, 51, 49-50.

33. Tasanen, K.; Varpuluoma, O.; Nishie, W. Dipeptidyl Peptidase-4 inhibitor-associated bullous pemphigoid. Front. Immunol. 2019, 10, 1238. [CrossRef]

34. Bach, J.F. Infections and autoimmune diseases. J. Autoimmun. 2005, 25, 74-80. [CrossRef]

35. Drago, F.; Nozza, P.; Casazza, S.; Brusati, C.; Bandelloni, R.; Rebora, A. Human herpesviruses in bullous pemphigoid lesions. Br. J. Dermatol. 2005, 152, 375-376. [CrossRef]

36. Blazsek, A.; Silló, P.; Ishii, N.; Gergerly, P., Jr.; Poor, G.; Preisz, K.; Hashimoto, T.; Medvecz, M.; Karpati, S. Searching for foreign antigens as possible triggering factors of autoimmunity: Torque Teno virus DNA prevalence is elevated in sera of patients with bullous pemphigoid. Exp. Dermatol. 2008, 17, 446-454. [CrossRef]

37. Min, M.; Damstetter, E.; Chen, A.Y.-Y. Autoimmune blistering disorders in the setting of human immunodeficiency virus infection. Int. J. Women's Dermatol. 2018, 4, 159-165. [CrossRef] [PubMed]

38. De, D.; Kanwar, A.J.; Radotra, B.D.; Narang, T. Bullous eruption in a patient infected with the human immunodeficiency virus. Skinmed 2008, 7, 98-101. [CrossRef]

39. Bull, R.; Fallowfield, M.; Marsden, R. Autoimmune blistering diseases associated with HIV infection. Clin. Exp. Dermatol. 1994, 19, 47-50. [CrossRef] [PubMed]

40. Jang, H.; Jin, Y.-J.; Yoon, C.H.; Kim, C.-W.; Kim, L. Bullous pemphigoid associated with chronic hepatitis C virus infection in a hepatitis B virus endemic area: A case report. Medicine 2018, 97, e0377. [CrossRef]

41. Batts, A.F.; Jalalat, S.Z.; Hunter-Ellul, L.; Wilkerson, M.G. Exacerbation of bullous pemphigoid after hand, foot, and mouth disease treated with rituximab. JAAD Case Rep. 2016, 2, 7-9. [CrossRef] [PubMed]

42. Löffel, F.B.; Stücker, M. Localized bullous pemphigoid triggered by erysipelas. Hautarzt 2016, 67, 829-832. [CrossRef]

43. Bornhövd, E.; Partscht, K.; Flaig, M.J.; Messer, G. Bullöse Skabies und durch Skabiesbefall getriggertes bullöses Pemphigoid [Bullous scabies and scabies-triggered bullous pemphigoid]. Hautarzt 2001, 52, 56-61. [CrossRef]

44. Castle, S.C.; Uyemura, K.; Fulop, T.; Makinodan, T. Host resistance and immune responses in advanced age. Clin. Geriatr. Med. 2007, 23, 463-479. [CrossRef] [PubMed]

45. Chinen, J.; Shearer, W.T. Secondary immunodeficiencies, including HIV infection. J. Allergy Clin. Immunol. 2010, 125 (Suppl. 2), S195-S203. [CrossRef]

46. Salemi, S.; D'Amelio, R. Could autoimmunity be induced by vaccination? Int. Rev. Immunol. 2010, 29, 247-269. [CrossRef] 
47. Amagai, M.; Ikeda, S.; Hashimoto, T.; Mizuashi, M.; Fujisawa, A.; Ihn, H.; Matsuzaki, Y.; Ohtsuka, M.; Fujiwara, H.; Furuta, J.; et al. A randomized double-blind trial of intravenous immunoglobulin for bullous pemphigoid. J. Dermatol. Sci. 2017, 85, 77-84. [CrossRef]

48. Brown, M.A.; Hatfield, J.K. Mast cells are important modifiers of autoimmune disease: With so much evidence, why is there still controversy? Front. Immunol. 2012, 3, 147. [CrossRef] [PubMed]

49. Ren, Z.; Narla, S.; Hsu, D.Y.; Silverberg, J.I. Association of serious infections with pemphigus and pemphigoid: Analysis of the Nationwide Inpatient Sample. J. Eur. Acad. Dermatol. Venereol. 2018, 32, 1768-1776. [CrossRef] [PubMed]

50. Germano, V.; Cattaruzza, M.S.; Osborn, J.; Tarantino, A.; Di Rosa, R.; Salemi, S.; D'Amelio, R. Infection risk in rheumatoid arthritis and spondyloarthropathy patients under treatment with DMARDs, corticosteroids and TNF- $\alpha$ antagonists. J. Transl. Med. 2014, 12, 77. [CrossRef] 